\title{
Can Hypernorms Be Justified? Insights From A Discourse-Ethical Perspective
}

\author{
Andreas Georg Scherer \\ University of Zurich
}

\begin{abstract}
I explore the role of hypernorms in the Integrative Social Contracts Theory (ISCT) of Thomas Donaldson and Thomas W. Dunfee, who suggested that hypernorms are a necessary condition for the rejection of cultural relativism and justification of moral norms within and across social communities. Hypernorms are, thus, a significant part of a conception of international business ethics. I highlight philosophical problems that emerge in attempts to identify and justify hypernorms. These problems have not been sufficiently addressed in the ISCT; therefore, I will discuss the discourse-ethical contributions of contemporary German philosophers toward resolving the justification problem with regards to universal norms. Discourse ethics builds on the linguistic and the pragmatic turns in philosophy and develops procedural rules for the assessment of norms. I explore variants of discourse ethics with regards to their concept of justification and discuss the implications of discourse ethical procedures for the justification of norms and actions.
\end{abstract}

KEY WORDS: constructivism, discourse ethics, hypernorms, Integrative Social Contracts Theory, linguistic turn, pragmatic turn

As soon as we reflect on a loss of naïve certainties, we no longer face a set of basic propositions that are "self-legitimating." That is there are no indubitable "starting points" beyond the bounds of language, no experiences that can be taken for granted within the bounds of reasons. (Habermas 2003a, 36)

I.

TWENTY YEARS AGO Thomas Donaldson and Thomas W. Dunfee (1994) 1 published "Toward a Unified Conception of Business Ethics: Integrative Social Contracts Theory." Five years later their Integrative Social Contracts Theory (ISCT) was further developed in their seminal book, Ties That Bind (Donaldson and Dunfee 1999a). The authors diagnosed incoherence and lack of direction not only in the academic discourse on business ethics, but also in management practice where global business firms operate in different environments, with heterogeneous social rules and moral expectations but without sufficient theoretical guidance. As a consequence, it is unclear what rules can be applied to the moral assessment of the behavior of global business firms.

In moral and social philosophy, social contract theory has a long tradition that essentially extends from thinkers of the Enlightenment, such as Thomas Hobbes, 
John Locke, and Jean-Jacques Rousseau, to more recent philosophers, such as John Rawls (1971) and David Gauthier (1986). Social contract theory explores the origins of society and suggests that individuals have implicitly or explicitly consented to submit themselves to the authority of societal institutions (e.g., state, laws, rules, morals) in exchange for the protection of their freedoms and rights as members of the society. In their Integrative Social Contracts Theory, Donaldson and Dunfee (1994, 1999a) build on this tradition and suggest that social norms and moral obligations can be explained and justified by contractual relationships among members of social communities. These contractual relationships are both hypothetical and factual, and exist on two societal levels: macrosocial and microsocial.

The "macrosocial" contract is conceived as a hypothetical contract to which all members of society implicitly consent. The macrosocial contract provides "objective background standards for social interaction" (Donaldson and Dunfee 1999a, 19) and "defines the normative ground rules" for "microsocial" contracts (Donaldson and Dunfee 1994, 254). The normativity of the macrosocial contract rests on the assumption that all rational humans consent, at least hypothetically, to the terms of the contract.

Microsocial contracts, by contrast, are nonhypothetical. They are often only informal (so-called "authentic") contracts between members of specific communities, such as corporations, industries, professional associations, trade associations, or national systems. Microsocial contracts define social rules and moral obligations that take account of particular circumstances and help cope with the complexity and varieties of conditions in the business world. They help toward making decisions that are morally acceptable within particular social communities.

The proposed "unified theory" of Donaldson and Dunfee aims at an integration of ethical perspectives in two respects. In the first, Donaldson and Dunfee want to bridge the gap between empirical and normative theory, that is, between theory that explains observable social phenomena and theory that prescribes certain behavior. The aim is to develop a theory that takes into account the various factors that influence individual behavior but that goes beyond mere explanation. Therefore, the authors want to propose a theory that helps decide the ethical acceptability of a certain behavior and provides guidance on what actors should do. By engaging with this endeavor, they "seek to put the 'is' and the 'ought' in symbiotic harmony" (Donaldson and Dunfee 1999a, 24).

In the second, Donaldson and Dunfee also want to bridge the gap between general ethical theories and local moral rules. The former operate on a high level of abstraction, while the latter are tailored to specific situations and take the values of particular social communities or cultures into account. The aim is to develop a higher-level ethical theory that embraces the heterogeneous social rules and moral norms of different cultural or national communities and helps assess the normative validity of these local rules across social communities.

\section{II.}

Donaldson and Dunfee reject cultural relativism and maintain that the authenticity of microlevel contracts does not guarantee their ethical acceptability and legitimacy 
across various cultural or national communities. They hold that "by insisting that any extant contracts cohere with the moral limits established by a broad macro or hypothetical contract, relativism is avoided" (Donaldson \& Dunfee 1999a, p. 20). The authors propose that there is evidence for the existence of so-called "hypernorms." Hypernorms are part of the macrosocial contract and limit the "moral free space" within which microsocial contracts can emerge and be considered justified.

Donaldson and Dunfee (1999b, p. 46) explain, "Hypernorms are principles so fundamental that, by definition, they serve to evaluate lower order norms, reaching to the root of what is ethical for humanity. They represent norms by which all others are to be judged." Donaldson and Dunfee (1999a, p. 50) emphasize the significance of hypernorms for ISCT and speak of them as "second-order moral concepts," and as "far-reaching norms [...] credited with independent status" and "considered as presumptive and axiomatic of the theory."

Thus the existence of hypernorms is considered a necessary condition for lower-level moral norms to develop within acceptable moral boundaries. Without such hypernorms, the Integrative Social Contract Theory will lead to cultural relativism. Cultural relativism, by definition, maintains that it is neither possible nor acceptable to judge the ethical validity of social norms or actions across different moral communities. ${ }^{1}$

The relativist view is grounded in the assumption that a person or culture believing an act is morally correct, helps make it morally correct —or at least to make it correct for that person or that culture. In its pure form, relativism would allow any individual or community to define ethically correct behavior in any way they wished. No matter how bizarre, their ethics would be on a par with everyone else's. (Donaldson \& Dunfee 1999a, p. 20)

Donaldson and Dunfee respond to the challenge of how to discover and to justify hypernorms with reference to the "existence of the convergence of religious, cultural, and philosophical beliefs around certain core principles" that may "serve as a clue, even if not as total validation, for the identification of hypernorms" (Donaldson and Dunfee 1994, 265). Later, they more cautiously formulate, "at least it is a reasonable hope that we should discern such a convergence" (Donaldson and Dunfee 1999a, 44).

The authors distinguish between three different categories of hypernorms (51-53): procedural, structural, and substantive. Procedural hypernorms specify the "rights of exit and voice essential to support microsocial consent" (51). Here they touch upon rules of argumentation as proposed by philosophers such as Jürgen Habermas (1990) and Robert Alexy (1989), but they do not explore this avenue further. Although Donaldson and Dunfee (1999a, 54-56) touch upon the role of language in normative or empirical inquiry, they treat language as a neutral tool for the transmission of meaning. However, they neglect an insight, gained from the linguistic turn in philosophy, which is that language has a constitutive role in the construction of normative or empirical knowledge (Habermas 2003a, 2003b).

Structural hypernorms entail principles that are essential for political and societal institutions to function properly, including the right to property, the right to fair treatment under the law, and the right to political participation. They discuss an "efficiency hypernorm" in detail (Donaldson and Dunfee 1999a, 117-38) and 
consider this structural norm an indispensible condition of economic activity, as it is essential for providing the necessary social goods in society. Their final typology consists of substantive hypernorms, "which specify fundamental conceptions of the right and the good" (52).

Donaldson and Dunfee suggest that procedural and structural hypernorms are more implicit in the hypothetical macrosocial contract and can thus be identified only with difficulty, whereas "substantive hypernorms are to be found on the outside. They are in effect, exogenous" (52). Purely procedural conceptions of morality are regarded as being "too thin" (56) because they do not define and prescribe particular moral values; the authors, therefore, suggest that procedural and structural hypernorms need to be supplemented by substantive norms. They build on the concept of moral minimalism proposed by Michael Walzer $(1994,18)$, which "consists in principles and rules that are reiterated in different times and places and that are seen to be similar even though they are expressed in different idioms and reflect different histories and different versions of the world."

Despite the significance of hypernorms, however, Donaldson and Dunfee make no attempt to further explore the philosophical status and justification. Donaldson and Dunfee (1999a, 14) touch on the philosophical difficulties of such an endeavor and maintain that a "view from nowhere," that is "a view that is universal, dispassionate, and impartial," is not feasible. However, they decline to take a position on whether hypernorms have a rational (as proposed in the Kantian tradition) or an empirical or historical foundation (as proposed in the Hegelian tradition), and even claim that it is not necessary to resolve the underlying epistemological questions in order to identify hypernorms (59). Instead, they claim to remain "agnostic on the ultimate source of hypernorms" (74).

Donaldson and Dunfee offer a kind of checklist that includes what they call "types of evidence" in support of a hypernorm presumption (60). The authors maintain that this checklist may help to confirm or disconfirm the presumption that a particular norm or principle can count as a hypernorm:

1. Widespread consensus that the principle is universal

2. Component of well-known global industry standards

3. Supported by prominent nongovernmental organizations such as the International Labour Organization or Transparency International

4. Supported by regional government organizations such as the European Community, the Organisation for Economic Co-operation and Development, or the Organization of American States

5. Consistently referred to as a global ethical standard by international media

6. Known to be consistent with precepts of major religions

7. Supported by global business organizations such as the International Chamber of Commerce or the Caux Round Table

8. Known to be consistent with precepts of major philosophies

9. Generally supported by a relevant international community of professionals, such as accountants or environmental engineers

10. Known to be consistent with findings concerning universal values

11. Supported by the laws of many different countries 
At the same time, they also provide a list of factors that may indicate counterevidence for the presumption of a hypernorm (60-61):

1. Evidence from the presumptive list to the contrary, for example, that the putative hypernorm principle does not represent a universal value

2. Evidence from the presumptive list in support of hypernorm status for a mutually exclusive principle

3. A decision context such that applying the presumptive hypernorm would result in the violation of a widely recognized human right

Donaldson and Dunfee (61-81) elaborate on issues such as international bribery, gender discrimination, market research, and workplace safety in order to show how one can assess whether a hypernorm applies when deciding whether or not a certain business behavior is ethically acceptable. Although they maintain that "the process is relatively easy and noncontroversial" (63), a closer inspection shows that a great deal of personal judgment is involved when Donaldson and Dunfee decide on these cases. And the criteria that are applied by both authors are not always clear (61-62). Why and under what conditions are international standards of nondiscrimination given preference over local laws? The authors refer, for example, to religiously grounded laws and customs in Saudi Arabia that prohibit women from driving. Why do the authors suggest that truth-telling, despite the widespread philosophical, religious, and legal mandate to tell the truth, should not be considered a hypernorm that must be applied in market research? In this case, the authors refer to consumer researchers who fail to reveal that they are not independent but were hired by a firm. Why and under what conditions are international standards of workplace safety given preference to local norms and customs? Here, the authors discuss whether safety standards should be waived at a Korean plant of a global chemical firm when workers refuse to wear helmets due to local customs.

III.

Donaldson and Dunfee's ISCT has been well received in the literature, inspired an intensive debate, and encouraged a wealth of theoretical and empirical studies (see, e.g., Brenkert 2009; Dempsey 2011; Dunfee, Smith, and Ross 1999; Hartman, Shaw, and Stevenson 2003; Robertson 2009; Spicer 2009; Wempe 2009). However, there have also been unresolved concerns with regards to the foundations of their framework (see, e.g., Calton 2006; Douglas 2000; Gilbert and Behnam 2009; Rowan 2001; Soule 2002; Soule, Hedahl, and Dienhart 2009; Steinmann and Scherer 1997, 1998a). Although Donaldson and Dunfee discuss the process of identifying hypernorms in some detail, a number of critical questions and interrelated issues still remain with regards to the search for and justification of hypernorms (see Dunfee 2006 for concessions). In the following I point to a few limitations of their framework.

\section{Justification of Hypernorms and "Types of Evidence"}

Donaldson and Dunfee do not elaborate on or justify their proposed checklists; in fact, their types of evidence and counterevidence appear ad hoc. It seems that the "types 
of evidence" enjoy a kind of metastatus as they serve as a kingmaker for hypernorms within the ISCT conception. Yet, their philosophical status is not further explored (see, e.g., Dunfee 2006, 305, on "praxis"). This is not a trivial issue as it is not clear whether and why any of these types of evidence deserve to be acknowledged as a warrant for the hypernorm status of a particular norm. When a business norm is consistent with so-called industry standards, precepts of major religions, and major philosophies, and supposedly supported by prominent NGOs and global business organizations, what does this tell us? Does this make the norm justified? Should we stop asking critical questions? Should we not be even more critical and aware that the types of evidence are likely to be influenced by prevailing ideologies, power differentials, and social imbalances (see, e.g., Banerjee, Chio, and Mir 2009; Berenskoetter and Williams 2007)? I am not convinced that the identification of hypernorms is as "easy and uncontroversial" as Donaldson and Dunfee (1999a, 63) explain. And even if it is "relatively easy" (63) in some cases, what do we do in all the other cases where it is difficult and controversial? Donaldson and Dunfee do not provide a solution for this problem and, Dunfee $(2006,308)$ concedes: "It is a fair conclusion that some of those applying ISCT have had nontrivial difficulties in identifying hypernorms."

\section{Methodological Issues}

Donaldson and Dunfee are not clear about whether the proposed list is complete — one could ask why the authors propose eleven types of evidence, and not ten or twelve? And why do they propose three types of counterevidence, and not two or four? Consequently, one may ask whether and under what conditions additional factors could or should be included, and when certain types of (counter)evidence should be replaced or abandoned. Indeed, if one explores the matter more deeply, a number of further methodological issues emerge that also need to be addressed. For example, it is not obvious on what scale of measure the hypernorm status of norms is intended to be understood (nominal, ordinal, or ratio scale) and how the scale of measure relates different hypernorms to each other. It is not obvious how the various types of evidence may be weighted or how evidence and counterevidence may be balanced against each other in order to address the emerging trade-offs. What should we do when we realize that there is no coherence between, say, industry standards, religious precepts, and what is supported by NGOs? It appears that one needs some form of metacriteria or metaprocedure to check and prioritize the various types of evidence in order to remedy these issues. Unfortunately, this is not provided; instead, Donaldson and Dunfee seem to abandon argumentation and argumentation rules as the key measures to resolve justification issues (see their critical remarks against procedural conceptions of morality, Donaldson and Dunfee 1999a, 55-56). The authors provide a list of rules of thumb that may help to arbitrate conflicts within and among communities (Donaldson and Dunfee 1999a, 179-91). However, these rules are not sufficient to set priorities among hypernorms.

\section{Power Games}

The authors seem to assume that the norms and values that are embedded both implicitly and explicitly in the various sources they refer to in their types of evidence are true 
(i.e., they are or can be identified and described correctly) and right (i.e., they rationally deserve agreement or can be defended rationally). Donaldson and Dunfee question neither their epistemic nor normative validity, but instead treat the types of evidence as self-evident. In particular, the authors neglect to consider that the various standards and institutions they refer to are often highly contested and likely to be the result of power games between opposing interests and/or epistemic or ideological positions (see, e.g., Banerjee, Chio, and Mir 2009; Bleiker 2000). This applies to governmental regulations and international institutions (Barnett and Finnemore 1999; Berenskoetter and Williams 2007) as much as to major philosophies (Baynes, Bohman, and McCarthy 1987) or social science paradigms (Burrell and Morgan 1979). Even more so, the authors neglect to consider that the precepts of major religions are inherently ideological in the sense that their rationality is not reflected and that their rules of conduct are not questioned (Foucault 1980). Therefore, one has to question whether these items can serve as evidence for the identification and justification of hypernorms.

\section{Moral Dilemmas and Paradoxes}

Donaldson and Dunfee seem to assume that all hypernorms are mutually compatible and thus provide a consistent and logically coherent set of rules. This is apparent, for example, in the proposed second counterevidence, which requires that hypernorm principles not be mutually exclusive. However, the authors fail to take into account that modern societies are complex and ambiguous. Seen from a global perspective, legal rules, cultural expectations, and moral values differ widely, not just across societies but also within. Legal fragmentation (Berman 2009; Michaels 2009; Young 2012) and cultural pluralism (Thomas 2000; Teubner and Korth 2012) seem to be characteristic of our (post)modern epoch. Today, societies consist of incompatible institutional and moral demands, and both individuals and business organizations have to resolve moral dilemmas (Calton and Payne 2003) and institutional complexity (see, e.g., Greenwood et al. 2011; Pache and Santos 2010). In international business, it is often possible to observe paradoxes when principles, norms, and values that are "contradictory yet interrelated [...] exist simultaneously and persist over time" (Smith and Lewis 2011, 382). Under these conditions, the assumption of the existence of a coherent set of hypernorms may be no more than what Donaldson and Dunfee see as something to "hope" for (Donaldson and Dunfee 1999a, 44).

\section{History and Learning}

The authors do not sufficiently discuss the conditions, possibilities, and limitations of learning at either the individual or community level. The types of evidence and the assumed hypernorms, it appears, are readily available, being ahistorical phenomena. Thus historical or spatial development is neither sufficiently addressed nor critically reconstructed. Hypernorms appear to be quite static, despite the well-balanced interrelationship between the macro and the micro levels of contracts in Donaldson and Dunfee's Integrative Social Contracts Theory and their reference to a possible "convergence." The conception does not sufficiently consider the historical or spatial dynamics of hypernorms, and their possible progression or regression. The hypernorms and the 
embedded "fundamental conceptions of the right and the good" (52) are not conceived of as a cultural phenomenon made by humans, with a history and an open future. Dunfee has also conceded this issue (see Dunfee 2006, 310-11) and Donaldson has only briefly commented on the dynamics of hypernorms (see Donaldson 2009).

\section{Regressions}

In the course of human and moral development, regressions cannot be excluded (Horkheimer and Adorno 1972). With their convergence rhetoric, however, Donaldson and Dunfee seem to implicitly assume that the various types of evidence are the result of a progressive development toward a stronger homogeneity and institutionalization of rules of ethical conduct. For example, that which is supported by regional government organizations, the "laws of many different countries," or the "global ethical standard by international media," among other types of evidence (Donaldson and Dunfee 1999a, 60), is considered appropriate benchmarks of ethical business conduct. However, these institutions may fail due to elitist discourses that focus only on technical rationality (Beck 2010; Crouch 2004), power games, lack of transparency within procedures (Barnett and Finnemore 1999; Mattli and Buthe 2003), or the influence of the media and strong industrial lobbying groups (Herman and Chomsky 1988; Marcuse 1964). These institutional failures may provoke moral regressions; for example, business firms and governmental institutions may abandon privacy rights or other human rights in the "war on terror" (Michaels 2008; Richards 2013). The involvement of some computer and software firms in the transfer of personal data to national intelligence agencies is just one of many examples of how ethical business conduct may be compromised (Greenwald 2014; Zuboff 2015).

In summary, Donaldson and Dunfee build on the hypothesized convergence of various international standards and institutions (mentioned in their types of evidence) and assume these standards and institutions are generally accepted across cultures. The authors are quite confident that such a convergence can be observed and confirmed in empirical research. On this basis they derive normative orientations for ethical business conduct in order to bridge the gap between what is and what ought to be. However, despite this sophisticated endeavor of an indirect justification of hypernorms, one may critically note that the selection process of hypernorms may be "self-serving" (Soule $2002,119)$ and possibly biased toward the preferences of particular social groups (e.g., white male academics from the West) (Shaw 2000), so that a considerable "risk of error and manipulation" (Soule 2002,119) cannot be avoided. Therefore, one may conclude that hypernorms are not sufficiently justified and "that the normative context of ISCT is too vague to serve the needs of students and practitioners" (115). ${ }^{2}$

As a result, fundamental philosophical questions remain: How can we identify hypernorms? And how can we justify hypernorms? I will approach these questions from a philosophical perspective.

IV.

The possibility of a universal justification of moral norms is a matter of intense debate in philosophy (see, e.g., Habermas 1994; MacIntyre 1988; Rorty 1986). 
The skepticism against universal justifications is widespread within schools of thought as different as positivist philosophy (Albert 1985; Popper 1959) and postmodern theory (Lyotard 1984). Three main arguments are advanced against the possibility of a universal justification of norms: logical impossibility, empirical infeasibility, and political undesirability.

Regarding logical impossibility, adherents of positivist philosophy such as Karl Popper (1959) or Hans Albert $(1985,1987)$ argue that logical deduction is the only proper form of justification in philosophy and the sciences (for a critical analysis, see Apel 1976, 1987; Mittelstrass 1985). The logical impossibility of a final justification can be shown when exploring the reasoning game between a proponent and an opponent who is a skeptic. If an opponent questions Assertion $\mathrm{A}^{3}$ put forward by a proponent, the proponent has to advance Assertion B from which Assertion A can logically be deduced, so that it logically follows from $B(B \rightarrow A)$. However, the opponent can respond by questioning Assertion B. Therefore, a final justification is not reached until the proponent can justify Assertion B. This makes it necessary to advance Assertion $C$ from which Assertion $B$ can then logically be deduced $(C \rightarrow B)$. However, Assertion $\mathrm{C}$ can again be questioned, which requires the proponent to advance Assertion D in support of Assertion C $(\mathrm{D} \rightarrow \mathrm{C})$, and so forth. As one can see, this process leads to an infinite regress, which is not sufficient for justification. Popper and Albert maintain that, logically, there are only two alternatives to avoid an infinite regress. One option is to advance an assertion whose validity has already been questioned in a previous step of the reasoning game. For example, Assertion A could be advanced as a justification for Assertion $\mathrm{C}(\mathrm{A} \rightarrow \mathrm{C})$. This, however, leads to a logical circle, which again is not sufficient for justification. The other option is to stop justifying, that is, to break off reasoning and instead to insist on the original Assertion A. This, however, will still leave the skeptical opponent unsatisfied. Therefore, neither infinite regress, logical circle, nor breaking off reasoning will resolve the logical problem of justification. ${ }^{4}$ Can this philosophical problem be resolved? If so, how? As I will show below, the challenge is twofold: to develop a suitable understanding of justification and to define the right starting point from which any justification can proceed.

The second argument is empirical infeasibility. A more empiricist variant of positivist philosophy relies less on logic and more on empirical insights. Empiricists suggest searching for social rules that are accepted across various social communities. Once such social rules are identified empirically, they may serve as candidates for universally accepted norms. However, empirical findings are not sufficient to justify normative claims, as this kind of reasoning comes into conflict with the so-called is-ought problem, as explained by Hume ([1739] 1896): What "should be" cannot simply be deduced from what "is." Thus, empirical conceptions need to avoid "an objectivist assimilation of our normative practices to observable events in the world" (Habermas 2003a, 23). Therefore, it is at issue whether and how social rules that are accepted within a particular community or even across multiple communities can be universalized so that they can be considered as justified in any social community. The challenge is to assess the validity of norms by showing how empirical acceptance can lead to universal justification. Donaldson and Dunfee, in seeking to avoid the 
impending is-ought problem, select a more sophisticated approach. They provide a list of types of evidence in order to argue for "the convergence of religious, cultural, and philosophical beliefs around certain core principles" (Donaldson and Dunfee 1994, 265). Evidently, they aim to derive some indirect support for hypernorms. However, as seen above, this does not work.

The third argument is political undesirability. Adherents of postmodernism reject the idea of a universal justification of social norms (Lyotard 1984; Rosenau 1992). For postmodernists, a universal justification is an attempt to make one particular opinion dominant over other opinions and to suppress and marginalize other voices. The aim of postmodernism, therefore, is to protect the pluralism of social communities with their heterogeneous values, norms, and lifestyles. It rejects the idea of convergence, homogeneity, and unity and instead favors divergence, heterogeneity, and difference. The elaborations by Clegg and Gray are exemplary of this kind of thinking:

In this phase of thought, which characterizes the current sociological thinking about globalization, there is a realization that convergence is neither necessary nor desirable; that individual entities differ greatly across national societies, as well as within them; that culture is critical; and that convergence is less likely and less productive than divergence. These themes become characteristic of postmodernism. (Clegg and Gray 1996, 299)

Postmodernists maintain that norms enjoy validity and acceptance only within social communities and should not be extended beyond the boundaries of a particular community. This is because applying the norms of one social community to another community can be considered a form of cultural imperialism (Beauchamp 2010), where one community dominates by imposing its views on other communities. The challenge is to find a way to universalize norms and institutions as much as possible, but only as much as necessary, in order to establish a peaceful plurality under the conditions of contemporary societies, with their pluralism of incompatible rules, values, and lifestyles (Lorenzen 1987a).

\section{$\mathrm{V}$.}

In the face of these problems, the universal justification of moral norms seems to be a challenging, if not an impossible, task. However, three variations of discourse-ethics in contemporary German philosophy take account of these challenges and develop answers to the problem of (universal) justification: (1) The transcendental-pragmatic philosophy of Karl-Otto Apel, (2) the universal-pragmatic philosophy of Jürgen Habermas, and (3) the methodical constructivist philosophy of the Erlangen School of Paul Lorenzen and others. ${ }^{5}$ Given the restrictions of this article, I can only describe the general ideas of these philosophies (for more detailed discussions, see Gethmann 1992; Scherer 2003, 2009; Scherer and Patzer 2011; Steinmann 2007; Steinmann and Scherer 1997, 1998a, 1998b; Wohlrapp 2014, xl-xliii).

First, I want to point out that these philosophical schools build on two achievements in contemporary philosophy: (1) the linguistic turn, and (2) the pragmatic turn. All three schools of thought also develop a certain conception 
of procedural ethics: they advance discourse ethics and justify procedural rules for an argumentation process that helps to assess the normative validity of moral rules and values.

The linguistic turn in philosophy (Rorty 1967, 1992) means that the philosophical analysis of phenomena must be conducted as the analysis of language use with regard to these phenomena. This builds on the insight that we do not have an uninterpreted or direct access to reality. Rather, our access is made possible and filtered by the use of language and conceptual schemes. Philosophy after the linguistic turn rejects the naïve realism that the world is out there and that our assertions about the world can be controlled by their correspondence with "reality" (see, critically, Rorty 1979). This idea of the linguistic turn has implications for both epistemic and normative claims (truth and morality) (Habermas 2003a, 2003b; Kamlah and Lorenzen 1984).

The pragmatic turn (Bernstein 2010) tells us that the subjects of philosophical analysis are not detached from actual practice, but are embedded in and enacted by practice. Therefore, all concepts we use are founded in practice and derive their meaning from practice. This has implications for how we cope with reality and how our language, actions, and experiences are controlled (Apel 1980; Kamlah and Lorenzen 1984; Lorenzen [1968]1987).

From a pragmatist perspective, reality is not something to be copied; we take note of it performatively — as the totality of resistances that are processed and are to be anticipatedand it makes itself known to us solely in the constraints to which our problem-solving activities and learning processes are subject. (Habermas 2003a, 27)

All three philosophical schools apply these ideas to the problem of justification. They aim to reconstruct the argumentation rules that one implicitly applies when arguing about the validity of normative claims.

All three philosophical approaches contribute to the development of discourse ethics, which is concerned with the justification of normative claims or moral truths (Gilbert and Behnam 2009; Habermas 1990, 1995a; Rasche and Scherer 2015; Scherer and Patzer 2011; Stansbury 2009). From a discourse-ethical perspective, the validity of moral claims cannot be justified by an isolated individual reflecting monologically upon the world, but can be validated only intersubjectively in argumentation processes. Therefore, discourse ethics aims to reconstruct the ideal communicative conditions under which individuals can check validity claims by way of rational argumentation. These ideal conditions serve as a "regulative idea": Only those norms can enjoy validity upon which a qualified consensus, that is, a consensus under ideal conditions among competent individuals who are affected by the norm, has been achieved. Discourse ethics is a deontological ethics insofar as it is rule based (with regards to rules of communication). And it is a cognitivist ethics insofar as it argues that the validity of moral claims can be checked analogous to the validity of truth claims. As I show, there are variations on how these communicative rules can be justified and whether and how they can be universalized so that they can be used as procedural hypernorms to check the validity of norms across different communities (for an overview, see, e.g., Scherer and Patzer 2011; Steinmann and Scherer 1998b). ${ }^{6}$ 
VI.

The transcendental pragmatics of Karl-Otto Apel (1976, 1980, 1987; for an overview, see Kettner 1996; Mendieta 2002) is part of the Kantian endeavor of transcendental philosophy that aims to reconstruct the a priori conditions of cognizing about an object of experience and cognition (cf. Kant 1996, 64). However, Apel abandons the solipsistic idea that the cognizing subject can monologically realize reality and develop knowledge in isolation from other cognizing subjects; rather, he considers communicative intersubjectivity as the key to realizing, understanding, and criticizing social phenomena. Apel develops a universal conception of discourse ethics referring to culturally invariant conditions of the possibility of communication. Apel claims to provide a universal concept of communication and an ultimate justification (Letztbegründung) of ethical principles. In particular, he assumes absolute validity for his proposed procedure of norm evaluation. Apel's concept of discourse ethics provides principles of argumentation that guide the procedure for the analysis of normative questions.

The ultimate justification of transcendental pragmatics rests on the concept of retorsion (performativer Selbstwiderspruch). This concept can be explained by pointing out the contradiction between the content of an assertion and the action of making an assertion. A skeptic who presents the argument that "There is no universal claim!" is asserting a universal claim, and by presenting the argument, contradicts its content. For Apel, it logically follows that universal claims exist and that they can be justified. Apel argues that the concept of retorsion can be employed not only to test factual assertions, but also to serve as a method in fictional debates with potential skeptics in order to reconstruct the rules of argumentation. Consequently, Apel explores hypothetical questions that a skeptical opponent may ask, and thus reconstructs the rules of argumentation that cannot be questioned without giving rise to self-contradiction.

In developing these rules, Apel argues that any participant who makes an assertion must already assume that it can be tested according to an implicit set of universal rules of argumentation. Thus, these rules apply to each participant in an argumentation, since a rejection of these rules would be self-contradictory, and not just on the level of language use but also on the level of actual deeds, which echoes the linguistic-pragmatic foundation of his conception. Thereby, the transcendental-pragmatic conception attempts to rescue a unified and universal notion of justification as "communicative reason," because anyone who argumentatively challenges an idea of communicative reason automatically makes use of it. The conception thus claims universal validity in all moral communities.

VII.

Habermas is the most prominent living member of the Frankfurt School of Social Research, the origin of what is known as "critical theory" (Rasmussen 1996; Scherer 2009). Habermas attempts to reconstruct the normative foundations of critical theory by focusing on the possibility of undistorted communication that is built into the structure of any language (Habermas 1976). Based on his close collaboration with 
Apel at the University of Frankfurt a. M. in Germany, Habermas (1976) further develops the insights of linguistic and pragmatic philosophers-for example, J. L. Austin, C. S. Pierce, and J. Searl, among others - and suggests that a speaker raises (up to) four validity claims when making an utterance. The first is intelligibility ${ }^{7}$ : the speaker claims that what he or she says can be understood. The second is truth: the speaker claims that his or her assertion is true. Third is rightness (or legitimacy), in which the speaker claims that he or she is entitled to make a claim; and fourth is sincerity: the speaker claims to be sincere. In principle, an opponent who is a skeptic can challenge any of these claims in a concrete discourse.

Habermas suggests that any participant in a communicative interaction presupposes that under ideal conditions his or her claims can be scrutinized and verified (or falsified) in an open discourse. Participants do so regardless of the fact that actual communication is systematically distorted (for example, by uneven distribution of power among the participants) and usually falls short of this ideal. Yet discussants are routinely making this counter-factual assumption because efforts of communication would otherwise fail or not even be attempted. The ideal conditions of a free and transparent discourse are characterized by Habermas $(1995 \mathrm{~b}, 56)$ as "the freedom of access, equal rights to participate, truthfulness on the part of participants, absence of coercion in taking positions and so forth." Habermas suggests that these conditions must be understood as the "unavoidable presuppositions of argumentation," which apply to any social community regardless of the culture or nation (Habermas 1995b, 56).

For Habermas, the postmodernist skepticism toward the unity of reason and criticism against conceptions of universal morality are valid concerns. However, he rejects the postmodern mistrust that universalism would assimilate heterogeneity, leveling cultural differences or marginalizing other voices. Instead, he defends his approach of what he thinks is a "properly understood" universalism (Habermas $2001 \mathrm{~b}, \mathrm{xxxv}$ ). The postmodern mistrust appears misleading, since a correctly understood community does not constitute itself through concrete material moral norms of how to live a good life, but rather through procedural norms of argumentation and the "negative idea of abolishing discrimination" (Habermas 2001b, xxxvi). With this argument, Habermas also counters criticism advanced against his discourse ethics because of its allegedly "thin" morality, in that it may not put sufficient emphasis on the promotion of particular moral values (see, for example, the criticism by Michael Walzer mentioned earlier).

Habermas presents a developed conception of discourse ethics that takes into account the differences between cultures with different values and morals. He explicitly wishes to avoid the "lingering foundationalism" in Apel's philosophy (see Habermas 1995b, 79). Thus, Habermas does not claim ultimate justification for his proposed ethical principles and the principles of argumentation. Instead, he points out that any philosopher is always embedded in the argumentative praxis of a specific "sociocultural form of life" where - for the time being - moral rules and values are taken for granted (Habermas 2001c, 2001d, 2003a, 2003b). He argues that although a philosopher can partly distance himself or herself from the social community in which he or she is embedded, the philosopher cannot entirely dispose of his or her cultural and historical legacy in order to acquire the perspective of a neutral 
observer from outside the social world (Habermas 1995b, 81 et seq.). Such a "view from nowhere," as Donaldson and Dunfee (1999a, 14) have called it, is not possible.

Habermas describes problem-solving behavior as emerging from the practices of the lifeworld, from background assumptions, routines, and practical dealings with the world, that are naïvely taken for granted as long as they work as an available and unproblematic resource to manage one's life. These assumptions are only challenged and problematized at pivotal points, for example, when routines fail or contradictions arise. "As a result, what has hitherto been taken for granted and thus accepted as valid comes to be seen as merely 'presumed truths,' that is, as fundamentally problematic truth claims" (Habermas 2003a, 39). It is only at these pivotal points that a transition from (more or less unreflective) action to reflective discourse takes place. In such instances, validity claims are checked to understand why there is a problem and to develop answers to questions of truth or rightness so that solutions to what has become problematical can be achieved.

In his elaborations on the implications of linguistic and pragmatic turns, Habermas (2003a) emphasizes the role of learning and explores the temporal and spatial dynamics of knowledge creation. In doing so, he argues, "subjects capable of speech and action, who can be affected by reasons, can learn-and in the long run even "cannot not learn"' (8). He suggests that this possibility of learning embraces both the epistemic and the moral dimension: "[T]hey learn just as much in the moral-cognitive dimension of interacting with one another as they do in the cognitive dimension of interacting with the world" (8). This is an important aspect in Habermas's more recent philosophical thinking. Habermas holds that we can revise our knowledge, regardless of whether it is conceptual, technical, or ethical-political, in the light of experiences that we make when coping with the world. This includes both the natural and the social worlds. "Empirical judgments are formed in learning processes and emerge from how problems are solved" (26). This is because "in our daily coping as well as in experiments, we rub up against constraints" (27).

With regard to the truth claims in the epistemic realm, these constraints are defined by the restrictions of an objective world that influence whether and to what extent our actions are successful or not. By conceding a "weak naturalism" of his conception (22-30), Habermas argues that truth claims are not merely checked on the level of language and controlled by the achieved consensus, but are also controlled vis-à-vis an objective world. The tricky question, however, is how these practical "constraints" can be understood in the moral realm where the restrictions are not determined by a natural world but are made by humans in the social world. Individuals are embedded in a particular social community where moral values, principles, and rules are taken for granted as sources for practical orientation. They are not questioned unless the practice fails and conflicts emerge (or are likely to emerge), and then these practical certainties are reconsidered. "Instead of the resistance of objects, which we run up against in the lifeworld, here we have the opposition of other social actors whose value orientation conflict with ours" (42). This marks an important difference on how epistemic and moral beliefs are controlled by coping with the world. "For moral beliefs do not falter against the resistance of an objective world that all participants suppose to be one and the same. Rather they falter against the irresolubility of normative 
dissensus among opposing parties in a shared social world" (Habermas 2003b, 256). This has consequences on how these problems may be resolved:

To be sure, moral beliefs do guide (normatively) rule-governed social interactions in a similar way that empirical beliefs guide goal-oriented interventions in the objective world. However, they are implicitly corroborated in a different way-not by successfully manipulating otherwise independently occurring processes, but by consensually resolving conflicts of interaction. (256)

With regards to social action within constitutional democracies, Habermas (2003a, 42-49) refers to the process of legislation with the help of which modern societies regulate conflicts among its members in a peaceful manner. He argues that this must be conceived of as an open process of constructing new rules in order to address new issues or unexamined situations that we experience the more complex societies become. With this conception, he breaks new ground and distances himself from the deontological natural law conceptions of morality: "Constructivism replaces the static eternal validity of natural law with a dynamic, prudential, and, at the same time, morally insightful process of legislation" (47).

However, what can serve as moral orientation for individuals and institutions from both posttraditional and traditional societies? How and in what sense can we build on and extend this model in order to address intercultural conflicts that take place outside the realm of democratic institutions? How should the relationship between theory and practice be adequately understood in order to address the problem of infinite regress? Here, the constructivist approach may be of help.

IX.

In critical debates with skeptical perspectives (see Section IV), the constructivist approach of the Erlangen School defends the feasibility of justification (Mittelstrass 1985). This approach was initiated by Paul Lorenzen and Wilhelm Kamlah at the University of Erlangen in Germany in the 1960s (Kamlah and Lorenzen 1984; Lorenzen 1987a, 1987b) and has been further developed since then (Butts and Brown 1989; Mittelstrass 2005-2016). Constructivism shares the sense for actual practices with the Habermasian approach, but goes beyond Habermas in two respects.

First, constructivists consider Habermas's pragmatic turn too superficial: "Habermas's perspective is 'pragmatic' in the sense of a moderate reference to lifeworld concerns and to the performative nature of speech. A reference to further praxes or even to the practice of research regarding problems of orientation cannot be found in his work" (Wohlrapp 2014, 299). By contrast, constructivists maintain that the meaning of moral concepts such as argumentation, reason, and norm can only be understood by referring to the constitutive role of social practices in which these words are embedded. This builds on the insight that "the meaning of a word is its use in the language" (Wittgenstein 2009, 43). This, of course, leads to the question of how cultural relativism can be avoided when normative concepts are not considered transcendental but are embedded in a particular practice of language use. Constructivism responds to these concerns by stating that reason is not to be 
understood as a universal criterion but as a cultural achievement, as a "culture of reason" (Kambartel 1984, 1989a, 1989b) that is based on an inclusive practice of peaceful conflict resolution by argumentation.

Second, Habermas's (1996) approach to discourse ethics assumes a context for conflict resolution that is already more or less institutionalized. Despite his focus on deliberations above and beyond political institutions of democratic society, his conception of deliberative democracy presumes these institutions (see, critically, Baur and Arenas, 2014). This makes it difficult to account for intercultural conflicts in (largely) unregulated environments or interactions where no mutually accepted rules exist. Constructivism, by contrast, explores how conflicts between incompatible values and forms of life can be addressed when a common, practical, institutional basis is severely lacking (see, particularly, Gethmann 1998; Wohlrapp 1998, 2014). This makes the constructivist approach helpful for exploring the role of hypernorms.

Constructivism conceives of actual practice as both the cause and the methodical starting point of theory building (Mittelstrass 1977; Scherer and Dowling 1995). It is based on the insight that human beings do possess capabilities to master their lives more or less successfully, even before they develop or apply any theories. Since practice is not always successful, theorizing becomes necessary in order to address problems. This is why practice can be considered the cause of theory building: If we were always successful in our lives, there would be no need for theory. Yet, because practice does not always fail, it becomes possible to build on these (partly) successful practices and routines as the ultimate condition and starting point of theoretical endeavors. In this sense, methodical reflection represents a stylized reconstruction of actual practices (see Lorenzen [1968]1987, 5).

[Constructivists] are concerned to show how the concepts of science result initially from activity involved in daily practical behavior. All theoretical concepts are grounded in distinctions made, practical orientations taken, in what Husserl in his later writings called the Lebenswelt, the pre-reflexive, pre-scientific, pre-philosophical world that nevertheless guides scientific and philosophical reflection. It is the familiar world in which we all live, a world taken for granted, [...] a world that is pragmatically a priori. (Butts and Brown 1989, xvi)

Thus, constructivism escapes the problem of infinite regress because it builds on actual practice as the uncircumventable a priori of theory building (Mittelstrass 1985):

[C]onstructivists are not faced with the embarrassment of an infinite regress that plagues various forms of fundamentalism in philosophy of science. In order to justify some claim $P$, they claim $Q$; in order to justify $Q$, they claim $R$, and so on; in principle the process never ends. But because constructivists locate the ultimate basis of theory in practical activity, they do not have this problem. Pragmatic operations, unlike propositional truth claims, are the kind of thing that does not stand in need of justification of any sort. A recipe works in application, or it does not. It is the aim of constructivist "reconstruction" to discover what activities and operations successfully generate the various concepts that are central to the sciences. (Butts and Brown 1989, xvii)

Following this perspective, Kambartel (1989b, 1989c, 1991, 1998) questions the possibility of developing a theoretical or — what Putnam $(1981,110)$ calls — a "criterial 
conception of rationality [...] according to which there are institutionalized norms which define what is or is not rationally acceptable." Kambartel suggests not applying a universal principle or rule of argumentation that transcends all social communities. Rather, we are participants in specific situations wherein we produce judgments and orientations for action. We learn the use of communicative reason by making use of different criteria as participants of a specific, shared culture in which we have become socialized. Only by being embedded in a particular practice can we become capable of argumentation and learn what it means to handle conflicts in a reasonable way. Hence, we are not born as reasonable beings but rather become such through socialization, education, and self-reflection (Kambartel 1989b). Consequently, Kambartel argues that any philosophical endeavors concerning communicative reason need, as a starting point, this culture of reason, since any notion of reason or other normative concepts such as argumentation, consensus, or norm cannot be understood without such a pragmatic being embedded in a particular practice. The notion of reason cannot be gained by a philosopher's theoretical reflection alone, but requires a close connection to its underlying practice.

Lorenzen's ([1981]1987, 1987a, 1987c, 1989) approach to political anthropology and political knowledge follows a similar path but is more specific with regards to the institutional embedding of communicative reason. According to Lorenzen (1987a), it is the task of ethical politics to peacefully mitigate the conflicts that arise within posttraditional societies due to the heterogeneity of values, expectations, and lifestyles of individuals. Lorenzen follows the pragmatic turn in philosophy by making the (at least partly) successful political practice of stabilizing peace through open discourses in democratic institutions the starting point of a methodical reflection on rational argumentation and the public use of reason (for related ideas on the priority of democratic practice to philosophy, see also Gethmann 1992; Habermas 2003a, 47-48; Rorty 1991). The argumentative practice of conflict resolution based on binding laws that are agreed upon in free and open public discourses contribute to stabilizing peace and help to transform the pluralism of incompatible values and expectations into a "plurality of mutually compatible life forms" (Lorenzen 1987a, 233 et seq.; translation by the author). In doing so, Lorenzen's approach differs from the universalistic conceptions of Apel and (the earlier) Habermas that reconstruct the conditions of communication by analyzing dyadic relationships between individuals. At the time of its publication, Lorenzen's approach (Lorenzen [1981] 1987, 1987a) seemed to preempt Habermas's (1996) later developments with regards to democratic discourses in institutional contexts and the pragmatic turn of Habermas's conception (Habermas 1998, 2003a, 2003b).

Whereas Lorenzen and Kambartel focus on conflict resolution and argumentation within posttraditional societies (see, critically, Gethmann 1992), Wohlrapp (1998, 2014) loosens this contextual condition and explores conflicts among representatives of traditional and posttraditional cultures, where " $[\mathrm{t}]$ here are no or too few unproblematic interactions which might be able to provide the practical basis for a common normative order" (Wohlrapp 1998, 58). How is social interaction possible when individuals do not share the same values and social skills as part of their respective culture? Wohlrapp $(1998,59)$ suggests a three-step procedure "in which interaction 
with members of foreign cultures is taken up and the form of this interaction is at once explored and shaped such that the separate forms of life become compatible." These three steps are experience, understanding, and producing peaceability. In the first step, individuals from different cultures encounter each other as unfamiliar beings and experience this encounter as something enriching or disturbing - the latter are the problematic cases. The second step is when individuals want to go beyond pure experiences and emotional reactions, so they reflect on the experience of foreignness in order to gain an understanding. However, this can only be achieved relative to one's own cultural horizon, that is, as an understanding of what is alien or foreign as a new variant of one's own possibilities:

[I]n order to bring this cognition about, we need something the same or corresponding to serve as an identification foil against which the differences appear as differences of form only. In this we complete a "distancing." On the occasion of the concrete experience of alienation, we can raise ourselves above the mere immersion or indeed imprisonment in a practice and language which we have grown used to. We can recall and examine our own conceptual contexts and the practical situations we find ourselves in so that these are opened for encountering what is unfamiliar. (Wohlrapp 1998, 60)

In situations where conflicts arise, experience and understanding are not sufficient to achieve peaceful coordination. Rather the opponents have to explore the third step, which is whether and how far the creation of compatibility is possible. In order to do so, "[i]t is reasonable in the process of arguing to leave aside accustomed peculiarities, if they generate incompatibilities, i.e., to distance oneself from them for the sake of peace" (65). In order to formulate a normative principle based in this insight, Wohlrapp $(2014,401)$ formulates a principle of transsubjectivity: "Put your subjectivity up for consideration." Transsubjectivity was originally introduced by Lorenzen (1987a), and Wohlrapp explains what it is and is not.

[It] is not the same as "intersubjectivity." While "intersubjectivity" denotes either the complete suppression of subjectivity [...] or a recognition of the merely factual subjectivity of the other [...], "transsubjectivity" refers to the heightening of subjectivity aimed at the potential for being compatible with the subjectivity of the Other. It is the middle ground between simple acceptance and complete suppression. The principle of transsubjectivity states that, beginning with my subjectivity, I put my actual ego up for consideration as well as heighten and transcend it by seeking to participate in a general human potential, which is only attainable by recognizing the subjectivity of the Other. (Wohlrapp 2014, 401)

Thus, creating permeability between cultural horizons is not a theoretical solution; it is a practical possibility. It is up to the opponents of intercultural conflicts to explore whether and how this is realized in a concrete situation. In order to engage in a process of mutual learning, all that is required is the willingness to open up one's own horizon. There is no guarantee for success, but in principle the possibility exists. Where there is no culture of reason yet established, Kambartel reminds us, a "common, reasonable life cannot be achieved in this case without some people first of all setting off without a safety net" (Kambartel 1989a, 87; translation by the author). 
$X$.

What can we learn from these discourse-ethical considerations for the resolution of the problem of justification of hypernorms? In order to draw a conclusion, I want to emphasize the following insights:

Priority of procedural rules. As we have seen, Donaldson and Dunfee did not sufficiently explore the significance of the procedure by which (hyper-)norms can be identified and justified (Gilbert and Behnam 2009; Shaw 2000). Therefore, I suggest building on the insights of discourse ethics and analyzing the argumentative process by which the validity of norms, even the validity of hypernorms, can be checked. The proposed conceptions of discourse ethics developed by the German philosophers Apel, Habermas, Lorenzen, and others can be considered a helpful contribution to the development of such a procedure. Unlike Donaldson and Dunfee, I therefore suggest giving priority to procedural rules that serve as metalevel rules for the assessment of structural and substantial (hyper)norms. This builds on the insight of the linguistic turn in philosophy: we have no other means to check the validity of truth and moral claims than by argumentation. In the literature, there have already been several fruitful suggestions on how to enrich Donaldson and Dunfee's ISCT with Habermas's discourse ethics (see, e.g., Calton 2006; Gilbert and Behnam 2009; Shaw 2000). My elaborations follow this path but go one step further. While these authors have taken the discourse-ethical approach and its argumentation rules for granted, I explore its justifications and limitations, especially with respect to discourses among members from radically different cultures and/or discourses outside the realm of institutionalized democratic politics (Gethmann 1992). Both conditions are characteristic of the global economy and the challenges of multinational corporations operating in different cultural and institutional environments (Steinmann and Scherer 1998a; Scherer and Palazzo 2011).

Discovering versus constructing solutions to moral conflicts. The argumentative procedure is open to any normative claims concerning values and moral rules to be validated, whether these are rationally acceptable or not. These normative claims can have their origin in any social or cultural community and can be checked within or across communities as long as those who are affected by these claims submit their views to a mutual learning process that is directed toward peaceful conflict resolution. This means that the argumentative procedure is not necessarily restricted to discovering rules, that is, to finding something that is already present in the world but has not yet been detected. It does not necessarily have to stay within the "moral free space" fenced off by some presumed substantive hypernorms. Without doubt, most conflicts can be resolved within the realm of present rules and hypernorms. But not all conflicts. Therefore, we have to include a creative element, a learning process of constructing new rules and new solutions, which are not readily available as new problems emerge. When "new issues arise, new norms must be developed and justified in light of new challenges in history" (Habermas 2003a, 44). Therefore, the search for hypernorms that are assumed to be already present in the world (as an convergence of social norms and institutions) may neither be necessary nor sufficient for the resolution of every conflict. Instead, in cases of conflicts among 
incompatible values and lifestyles that are radically different from each other, new rules for peacefully living with each other may need to be developed that go beyond what has been envisioned as hypernorms.

Begin with practice versus with theory. To avoid the logical problems of justification, we cannot start with theory, moral axioms, first principles, or "types of evidence," but we have to begin with actual practice in order to avoid the pending infinite regress; we must reconstruct the rules of rational argumentation in actual practice. This takes into account the pragmatic turn in philosophy. The suggestions made by Apel, Habermas, and the constructivist philosophers demonstrate what such a beginning in practice may look like. However, we have to start in a concrete practice, a certain moral community or "form of life." With this selection, we cannot assume the universality of the values and the moral rules of that practice right from the beginning (Gethmann 1992). Any "evidence" of hypernorms that are assumed to prevail within or across particular practices and institutions does not provide a proper justification for the validity of these norms. We cannot assume a position outside the social world, a "view from nowhere" as Donaldson and Dunfee (1999a, 14) call it, in order to construct checklists for assessing the social world and its norms. Rather, we have to start from within, from a "culture of reason" and its aim for peace by argumentation (Gethmann 1992).

Culture of reason. When referring to practice, I suggest beginning with the culture of reason (Kambartel 1984, 1989b) that has developed in posttraditional societies and that aims at the peaceful resolution of conflicts (Lorenzen 1987a). Moral communities that do not aim for the peaceful resolution of conflicts do not need discourse ethics. This does not mean that discourse ethics are unjustified; rather, in this case, discourse ethics do not have a pragmatic function. Therefore, the "will of the citizen to have peace" (Gethmann 1992, 151; translation by the author) provides the socio-cultural precondition. Without such a will, the public use of reason would not have a function in society, and consequently we would not be able to distinguish between reason and nonreason. To explain the characteristics of the culture of reason, we can include the following from Kambartel (1989b, 42, translation by the author; see also Steinmann and Scherer 1998a, 31-32):

- In certain situations (in various respects), we draw on generally formulated (and addressed) orientations.

- Reasonable consideration does not recognize any privileged positions grammatically, either on the level of participation or on the level of argumentation.

- We acknowledge the interests of others and include those affected as a perspective for our considerations.

- We renounce the limited perspective of our own life and interest situations in favor of those of an impartial consideration.

- We orient ourselves in view of a freely shared human community.

- In connection with the foregoing, we also orient ourselves for reciprocal moral recognition of the other person.

These characteristics resemble conditions that are often linked with Habermasian discourse ethics, where criteria such as nonprejudice, nonpervasiveness, or noncoercion are used to define the ideal speech situation. In the constructivist conception, however, 
these characteristics have a different foundation. They are used not as criteria that are derived from a reflection on the presuppositions of the possibility of argumentation, but rather as "surfacing illustrations (Erläuterungen)" (Steinmann and Scherer 1998a, 32) of the cultural practice in which we are embedded:

The conceptual differentiation of practical reason, which we come up against under the headings of self-determination, recognition, equality, justice, etc., can only be unfolded in its essence from the inside, i.e., only in accompaniment to our practical entry into practice and experience of a particular condition of life. The reasons and judgments which are based on this conceptual landscape cannot even be suitably understood without us taking part to a certain extent in the form of life in which these judgments intervene for orientation. (Kambartel 1998, 122, translation by the author)

Universalization as a possible but not (always) necessary endeavor. Rational argumentation aims at the peaceful solution of particular conflicts among particular opponents. Whether there is a need for universalization depends on the specifics of the situation and whether and how others are affected by the possible solutions (Kambartel 1991, 1992). Constructive philosophy, therefore, does not aim for universal justifications of any moral claim but rather for universalization that goes only as far as the specific circumstances require (Gethmann 1992; Kambartel 1989a). Any consensus concerning values or norms that is reached under ideal or almost ideal conditions is assumed to be valid only among those who have taken part in the argumentation process. However, it may turn out to be a false consensus. The validity of normative claims may be challenged by new evidence or by new actors entering the discourse. Therefore, "the unconditional nature of moral validity claims can be accounted for in terms of the universality of a normative domain that is to be brought about" (Habermas 2003b, 261). This implies an inclusive argumentation process in which universality is constructed as far as other perspectives are included in the discourse (Gethmann 1992). Thus, universalization is conceived of as a possible but not (always) necessary endeavor. As a result there is no need to universally justify substantial hypernorms or to enforce a "fundamental conception of the right and the good" (Donaldson and Dunfee 1999a, 52). Rather, intercultural conflict resolution is an ongoing process of inclusion of "the other" into the culture of reason that is conceived of as a community with flexible boundaries (see Gethmann 1992). This resembles recent ideas on the inclusion of the other proposed by Habermas:

Equal respect for everyone is not limited to those who are like us. It extends to the person of the other in his or her otherness. And solidarity with the other as one of us refers to the flexible "we" of a community that resists all substantive determination and extends its permeable boundaries even further. (Habermas 2001b, xxxv-xxxvi)

Peaceful conflict resolution and mutual learning. In the process of human development, regressions cannot be principally avoided or excluded. What Huntington (1996) described as a "clash of civilizations" almost twenty years ago has become only one aspect of a great number of intercultural problems for humankind (e.g., ethnic conflicts, displacement of people, growing fundamentalism, inequality) that constitute major threats for peace. The culture of reason has the potential to contribute to the resolution 
of intercultural conflicts, both in business and in politics, but it does not deliver a guarantee. It is not up to philosophers to bring the world to reason by brandishing a philosophical concept (Rorty 1986). Rather, it is up to us, i.e. anybody who is already part of the culture of reason, whether we will expand the potential of the culture of reason and include others in the underlying practice by sharing the experience of peaceful conflict resolution with the help of free and open discourse (Kambartel 1998; Habermas 2001a, 2003a, 2003b). Likewise, it is up to us (and anybody who is part of the culture of reason) whether we live by the principles of transsubjectivity (Lorenzen 1987a; Wohlrapp 2014), are open enough to suspend our prejudices (and eventually norms that we conceive of as hypernorms today) in order to learn from others for the sake of peace, and extend our practices and develop new rules for tomorrow (Wohlrapp 1998; Habermas 2001a). By including the Other into our practices and letting ourselves be included by Others into their practices, we will be able to learn from one another and to jointly and actively shape a peaceful future for humankind.

\section{ACKNOWLEDGEMENT}

I thank the editors, one anonymous reviewer, and Emilio Marti for helpful comments. I thank Ann Nelson for her help with the English language and final editing. Address: Andreas Georg Scherer, University of Zurich, Universitätsstrasse 84, CH-8006 Zurich, Email: andreas.scherer@uzh.ch.

\section{NOTES}

1. Donaldson and Dunfee $(1999,23)$ define cultural relativism as follows: "No ethical view held by one culture is better than any other view held be another culture. "By contrast, Beauchamp (2010, 237) defines cultural relativism as a descriptive concept that does not preclude "basic, universal principles that cross cultural lines." The existence of such principles is only excluded in what Beauchamp calls "normative relativism."

2. In addition to these concerns, one reviewer of this article pointed out that the "entire 'contract' construction seems to play no role at all in the derivation of these hypernorms."

3. Assertion A can be a truth statement or a normative statement, so that the skeptic's argument in principle applies to both empirical and ethical knowledge.

4. This problem has been discussed in philosophy under various designations, for example, MünchhausenTrilemma (Albert 1985), Fries Trilemma (Popper 1959), and Agrippa's Trilemma (Klein 2009). For a critical analysis of this trilemma, see Apel 1987; Mittelstrass 1985. On skepticism and justification, see Audi 2011; Floridini 1996.

5. The philosophers related to the three discourse-ethical perspectives worked at the Universities of Frankfurt a. M. (Apel, Habermas), Erlangen-Nuremberg (Kamlah, Lorenzen), and Konstanz (Kambartel, Mittelstrass). In 1969 at a philosophical congress, Habermas and Lorenzen both held lectures on the discursive justification of norms. They were aware of the similarity in their approaches (cf. Wohlrapp 2014, xl); however, except for occasional references, they did not systematically engage with each other's work. Instead, constructivists emphasize the distinctiveness of constructive philosophy and normally do not use the term "discourse-ethics" as a label for their approach. Mittelstrass was a student of Kamlah in Erlangen, and went to Konstanz in the early 1970s to join Kambartel. Kambartel went to Frankfurt in 1993, after Apel's retirement. Wohlrapp was a student of Lorenzen in Erlangen and of Kambartel and Mittelstrass in Konstanz before he went to Hamburg. Gethmann, though trained and working elsewhere, collaborated closely with the constructivists. Even though some of the protagonists had already retired, the constructivist spirit was still present during my tenure at the Universities of Erlangen-Nuremberg (1990-2000) and Konstanz (20002002). In particular, it was influential in the development of a German business ethics approach that is based on discourse-ethical perspectives (Steinmann and Löhr 1989, 2015). 
6. In order to emphasize the distinctiveness of their approach to the justification of norms, constructivists tend to avoid using "discourse-ethics" as a label for their own philosophical endeavor (Lorenzen 1989, 54).

7. In his subsequent works, Habermas dropped the validity claim to intelligibility and focused on the remaining three claims.

\section{REFERENCES}

Albert, H. 1985. Treatise on Critical Reason. Princeton, NJ: Princeton University Press. 1987. "Science and the Search for Truth: Critical Rationalism and the Methodology of Science." In Rationality: The Critical View, edited by Agassi, J. and Jarvie, I. C., 69-82. Dortrecht, Netherlands: Martinus Nijhoff.

Alexy, R. 1989. A Theory of Legal Argumentation: The Theory of Rational Discourse as Theory of Legal Justification. Oxford: Clarendon.

Apel, K.-O. 1976. Sprechakttheorie und transzendentale Sprachpragmatik. Zur Frage ethischer Normen. In Sprachpragmatik und Philosophie, edited by Apel, K. O., 10-173. Frankfurt am Main: Suhrkamp.

1980. Towards a Transformation of Philosophy. Routledge: London.

. 1987. "The Problem of Philosophical Foundations in Light of a Transcendental Pragmatics of Language." In After Philosophy: End or Transformation?, edited by Baynes, K., Bohman, J., and McCarthy, T., 250-90. Cambridge, MA: MIT Press.

Audi, R. 2011. Epistemology: A Contemporary Introduction to the Theory of Knowledge, 3rd ed. New York: Routledge.

Banerjee, S. B., Chio, V., and Mir, R., eds. 2009. Organizations, Markets and Imperial Formations: Towards an Anthropology of Globalization. Cheltenham, UK: Edward Elgar.

Barnett, M. N., and Finnemore, M. 1999. "The Politics, Power, and Pathologies of International Organizations.” International Organization 53: 699-732.

Baur, D., and Arenas, D. 2014. "The Value of Unregulated Business-NGO Interaction:

A Deliberative Perspective." Business \& Society 53: 157-86.

Baynes, K., Bohman, J., and McCarthy, T., eds. 1987. After Philosophy: End or Transformation? Cambridge, MA: MIT Press.

Beck, U. 2010. "Climate for Change, or How to Create a Green Modernity." Theory, Culture \& Society 27: 254-66.

Berenskoetter, F., and Williams, M. J., eds. 2007. Power in World Politics. New York: Routledge.

Berman, P. S. 2009. "The New Legal Pluralism." Annual Review of Law and Social Science 5: 225-42.

Bernstein, R. J. 2010. The Pragmatic Turn. Cambridge: Polity Press.

Beauchamp, T. L. 2010. "Relativism, Multiculturalism, and Universal Norms: Their Role in Business Ethics." In The Oxford Handbook of Business Ethics, edited by Brenkert, G. G. and Beauchamp, T. L., 235-66. Oxford: Oxford University Pres.

Bleiker, R. 2000. Popular Dissent, Human Agency and Global Politics. Cambridge: Cambridge University Press.

Brenkert, G. G. 2009. "ISCT, Hypernorms, and Business: A Reinterpretation.” Journal of Business Ethics 88: 645-58.

Burrell, G., and Morgan, G. 1979. Sociological Paradigms and Organisational Analysis. London: Heinemann.

Butts, R. E., and Brown, J. R., eds. 1989. Constructivism and Science: Essays in Recent German Philosophy. Dortrecht, Netherlands: Kluwer Academic Publishers. 
Calton, J. M. 2006. "Social Contracting in a Pluralist Process of Moral Sense Making:

A Dialogical Twist on the ISCT.” Journal of Business Ethics 68: 329-46.

Calton, J. M., and Payne, S. L. 2003. “Coping with Paradox.” Business \& Society 42: 7-42.

Clegg, S., and Grey, J. T. 1996. "Metaphors of Globalization." In Postmodern Management and

Organization Theory, edited by Boje, D. M., Gephart, R. P. Jr., and Thatchenkery, T. J., 293-307. London: Sage.

Crouch, C. 2004. Post-Democracy. Malden, MA: Polity.

Dempsey, J. 2011. "Pluralistic Business Ethics: The Significance and Justification of Moral Free Space in Integrative Social Contracts Theory." Business Ethics-A European Review 20(3): 253-266.

Donaldson, T. 2009. "Compass and Dead Reckoning: The Dynamic Implications of ISCT." Journal of Business Ethics 88: 659-64.

Donaldson, T., and Dunfee, T. W. 1994. "Toward a Unified Conception of Business Ethics: Integrative Social Contracts Theory." Academy of Management Review 19: 252-84.

- 1999a. Ties That Bind: A Social Contracts Approach to Business Ethics. Cambridge, MA: Harvard Business School Press.

. 1999b. "When Ethics Travel: The Promise and Peril of Global Business Ethics." California Management Review 41(4): 45-63.

Douglas, M. 2000. "Integrative Social Contracts Theory: Hype over Hypernorms.” Journal of Business Ethics 26: 101-10.

Dunfee, T. W. 2006. "A Critical Perspective of Integrative Social Contracts Theory: Recurring Criticisms and Next Generation Research Topics." Journal of Business Ethics 68: 303-28.

Dunfee, T. W., Smith, N. C., and Ross, W. T. 1999. "Social Contracts and Marketing Ethics." Journal of Marketing 64(3): 14-32.

Floridini, L. 1996. Skepticism and the Foundation of Epistemology: A Study in the Metalogical Fallacies. Leiden: Brill.

Foucault, M. 1980. Power/Knowledge. Selected Interviews \& Other Writings 1972-1977. New York: Pantheon.

Gauthier, D. 1986. Morals by Agreement. Oxford: Oxford University Press.

Gethmann, C. F. 1992. Universelle praktische Geltungsansprüche. Zur philosophischen Bedeutung der kulturellen Genese moralischer Überzeugungen. In Entwicklungen in der methodischen Philosophie, edited by Janich, P., 148-75. Frankfurt am Main: Suhrkamp.

. 1998. "Reason and Cultures: Life-World as the Common Ground of Ethics." In Working Across Cultures, edited by Lange, H., Löhr, A., and Steinmann, H., 213-34. Dortrecht, Netherlands: Kluwer.

Gilbert, D. U., and Behnam, M. 2009. "Advancing Integrative Social Contracts Theory: A Habermasian perspective." Journal of Business Ethics 89: 215-34.

Greenwald, G. 2014. No Place to Hide: Edward Snowden, the NSA, and the U.S. Surveillance State. New York: Metropolitan Books.

Greenwood, R., Raynard, M., Kodeih, F., Micoletta, E. R., and Lounsbury, M. 2011. "Institutional Complexity and Organizational Response." Academy of Management Annals, 5: 317-71.

Habermas, J. 1976. "What is Universal Pragmatics?" In Habermas, J. On the Pragmatics of Communication, 21-102. Cambridge, MA: MIT Press. 1990. Moral Consciousness and Communicative Action. Cambridge, MA: MIT Press. 
. 1994. "The unity of reason in the diversity of its voices." In Habermas, J. Postmetaphysical Thinking: Political Essays, 115-148. Cambridge, MA: MIT Press. . 1995a. Justification and Application. Remarks on Discourse Ethics, 2nd printing. Cambridge, MA: MIT Press.

1995b. "Remarks on Discourse Ethics." In Habermas, J. Justification and Application: Remarks on Discourse Ethics, 19-111. Cambridge, MA: MIT Press. . 1998. Between Facts and Norms: Contributions to a Discourse Theory of Law and Democracy. Cambridge: Polity Press.

2001a. The Inclusion of the Other: Studies in Political Theory. Cambridge, MA: MIT Press.

- 2001b. Preface to Habermas, J. The Inclusion of the Other: Studies in Political Theory: xxxv-xxxvii. Cambridge, MA: MIT Press.

2001c. "A Genealogical Analysis of the Cognitive Content of Morality." In Habermas, J. The Inclusion of the Other: Studies in Political Theory, 3-46. Cambridge, MA: MIT Press.

. 2001d. 'From Kant's 'Ideas' of Pure Reason to the 'Idealizing' Presuppositions of Communicative Action: Reflections on the Detrancendentalized 'Use of Reason."' In Pluralism and the Pragmatic Turn: Essays in Honor of Thomas McCarthy, edited by Regh, W. and Bohman, J. (Eds.), 11-39. Cambridge, MA: MIT Press.

. 2003a. "Introduction: Realism after the Linguistic Turn." In Habermas, J. Truth and Justification, 1-49. Cambridge: Polity Press.

— 2003b, "Rightness Versus Truth: On the Sense of Normative Validity in Moral Judgments and Norms.” In Habermas, J. Truth and Justification, 237-75. Cambridge: Polity Press.

Hartman, L. P., Shaw, B., and Stevenson, R. 2003. "Exploring the Ethics and Economics of Global Labor Standards: A Challenge to Integrated Social Contract Theory." Business Ethics Quarterly 13: 193-220.

Herman, E. S., and Chomsky, N. 1988. Manufacturing Consent: The Political Economy of the Mass Media. New York: Pantheon.

Horkheimer, M., and Adorno, T. W. 1972. Dialectic of Enlightenment. Translated by Cumming, J. New York: Herder and Herder.

Hume, D. [1739] 1896. A Treatise of Human Nature. 3 vols. Oxford: Clarendon Press. Huntington, S. P. 1996. The Clash of Civilizations. New York: Simon \& Schuster.

Kambartel, F. 1984. The Grammatical Culture of Reason. Unpublished manuscript presented at a seminar meeting. University of Konstanz, Germany. . 1989a. Philosophie der humanen Welt. Frankfurt am Main: Suhrkamp. 1989b. Vernunft: Kriterium oder Kultur? Zur Definierbarkeit des Vernünftigen. In Kambartel, F. Philosophie der humanen Welt, 27-43. Frankfurt am Main: Suhrkamp. . 1989c. Begründungen und Lebensformen. Zur Kritik des ethischen Pluralismus. In Kambartel, F. Philosophie der humanen Welt, 44-58. Frankfurt am Main: Suhrkamp. . 1991. Versuch über das Verstehen. Der Löwe spricht... und wir können ihn nicht verstehen. In Ein Symposium an der Universität Frankfurt anlässlich des hundertsten Geburtstags von Ludwig Wittgenstein, 121-37. Frankfurt am Main: Suhrkamp.

1992. Die Vernunft und das Allgemeine. Zum Verständnis rationaler Sprache und Praxis. Perspektiven des Perspektivismus. Gedenkschrift zum Tode Friedrich Kaulbachs, edited by Gerhardt, V. \& Herold, N. (Eds.), 265-77. Würzburg, Germany: Koenigshausen-Neumann.

1998. Zur Grammatik von Wahrheit und Begründung. In Zwischen Universalismus und Relativismus. Philosophische Grundlagenprobleme des interkulturellen 
Managements, edited by Steinmann, H. and Scherer, A. G., 106-25. Frankfurt am Main: Suhrkamp.

Kamlah, W., and Lorenzen, P. 1984. Logical Propaedeutic: Pre-School of Reasonable Discourse. Lanham, MD: University Press of America.

Kant, I. 1996. Critique of Pure Reason. Translated by Pluhar, Werner S. Indianapolis: Hackett. Kettner, M. 1996. "Karl-Otto Apel's Contribution to Critical Theory." In Handbook of Critical Theory, edited by Rassmussen, D., 258-86. London: Basil Blackwell.

Klein, P. D. 2009. "Contemporary Responses to Agrippa's Trilemma.” In The Oxford handbook of skepticism, edited by Greco, J. Oxford Handbooks Online. doi: 10.1093/oxfordhb/9780195183214.003.0023.

Lorenzen, P. (1968)1987. Methodical Thinking. In Lorenzen, P. Constructive Philosophy, 3-29. Translated by Pavlovic, K. R. Amherst: University of Massachusetts Press. . (1981)1987. "Political Anthropology." In Lorenzen, P. Constructive Philosophy, 42-55. Translated by Pavlovic, K. R. Amherst: University of Massachusetts Press.

- 1982. Ethics and the Philosophy of Science. In Vol. 1 of Contemporary Germany Philosophy, edited by Christensen, D. E. (Ed.), 1-14. University Park: Pennsylvania State University Press.

. 1987a. Lehrbuch der konstruktiven Wissenschaftstheorie. Mannheim, Germany: BI Verlag.

1987b. Constructive Philosophy. Amherst: University of Massachusetts Press. 1987. "Critique of Political and Technical Reason." Synthese 71: 127-219.

1989. Philosophische Fundierungsprobleme einer Wirtschafts und Unternehmensethik. In Unternehmensethik, edited by Steinmann, H. and Löhr, A., 25-57. Stuttgart: Poeschel.

Lyotard, J. F. 1984. The Post-Modern Condition: A Report on Knowledge. Minneapolis: University of Minnesota Press.

MacIntyre, A. 1988. Whose Justice? Which Rationality? Notre Dame, IN: University of Notre Dame Press.

Marcuse, H. 1964. One-Dimensional Man: Studies in the Ideology of Advanced Industrial Society. Boston: Beacon Press.

Mattli, W., and Buthe, T. 2003. "Setting International Standards: Technological Rationality or Primacy of Power?" World Politics 56: 1-42.

Mendieta, E. 2002. The Adventures of Transcendental Philosophy: Karl-Otto Apel's Semiotics and Discourse Ethics. Oxford: Rowman \& Littlefield.

Michaels, J. D. 2008. "All the President's Spies: Private-Public Intelligence Partnerships in the War on Terror." California Law Review 96: 901-66.

Michaels, R. 2009. "Global Legal Pluralism.” Annual Review of Law and Social Science 5: 243-62.

Mittelstrass, J. 1977. “Changing Concepts of the A Priori.” In Historical and Philosophical Dimensions of Logic, Methodology and Philosophy of Science, edited by Butts, R. E. and Hintikka, J., 113-28. Dordrecht, Netherlands: Reidel. . 1985. "Scientific Rationality and Its Reconstruction." In Reason and Rationality in Natural Science, edited by Rescher, N., 83-102. Lanham, MD: University Press of America.

Mittelstrass, J. (Ed.). 2005-2016. Enzyklopädie Philosophie und Wissenschaftstheorie. (2nd ed.). Vols. 1-8. Stuttgart: Metzler.

Pache, A.-C., and Santos, F.. 2010. "When Worlds Collide: The Internal Dynamics of Organizational Responses to Conflicting Institutional Demands.” Academy of Management Review 35: 455-76. 
Popper, K. R. 1959. The Logic of Scientific Discovery. London: Hutchinson.

Putnam, H. 1981. Reason, Truth, and History. Cambridge, MA: Cambridge University Press.

Rasche, A., and Scherer, A. G. 2015. Jürgen Habermas and Organization Studies: Contributions and Future Prospects. In The Oxford Handbook of Sociology, Social Theory and Organization Studies: Contemporary Currents, edited by Adler, P., du Gay, P., Morgan, G., and Reed, M., 158-81. Oxford: Oxford University Press.

Rasmussen, D., ed. 1996. Handbook of Critical Theory. London: Basil Blackwell.

Rawls, J. 1971. A Theory of Justice. Cambridge, MA: Belknap.

Richards, N. M. 2013. “The Dangers of Surveillance.” Harvard Law Review 126: 1934-65.

Robertson, D. C. 2009. "Corporate Social Responsibility and Different Stages of Economic Development: Singapore, Turkey, and Ethiopia.” Journal of Business Ethics 88: 617-33.

Rorty, R., ed. 1967. The Linguistic Turn: Essays in Philosophical Method. Chicago: University of Chicago Press.

Rorty, R. 1979. Philosophy and the Mirror of Nature. Princeton, NJ: Princeton University Press.

. 1986. "Solidarity or Objectivity?" In Post-Analytic Philosophy, edited by Rajchman, J. and West, C., 3-19. New York: Columbia University Press. . 1991. "The Priority of Democracy to Philosophy." In Vol. 1, Objectivity, Relativism, and Truth: Philosophical Papers, edited by Rorty, R., 175-96. Cambridge: Cambridge University Press.

Rorty, R., ed. 1992. The Linguistic Turn: Essays in Philosophical Method, 2nd ed. Chicago: University of Chicago Press.

Rosenau, P. M. 1992. Post-Modernism and the Social Sciences: Insights, Inroads, and Intrusions. Princeton, NJ: Princeton University Press.

Rowan, J. R. 2001. "How Binding the Ties? Business Ethics as Integrative Social Contracts." Business Ethics Quarterly 11: 379-90.

Scherer, A. G. 2003. Multinationale Unternehmen und Globalisierung. Heidelberg: Physica.

. 2009. "Critical Theory and Its Contribution to Critical Management Studies." In The Oxford Handbook of Critical Management Studies, edited by Alvesson, M., Bridgman, T., and Willmott, H. (Eds.): 29-51. Oxford: Oxford University Press.

Scherer, A. G., and Dowling, M. 1995. "Towards a Reconciliation of the Theory Pluralism in Strategic Management: Incommensurability and the Constructivist Approach of the Erlangen School.' In Advances in Strategic Management, edited by Shrivastava, P. and Stubbart, C., 12A: 195-248. Greenwich, CT: JAI Press.

Scherer, A. G., and Palazzo, G. 2011. "The New Political Role of Business in a Globalized World: A Review of a New Perspective on CSR and Its Implications for the Firm, Governance and Democracy." Journal of Management Studies 48: 899-931.

Scherer, A. G., and Patzer, M. 2011. "Beyond Universalism and Relativism: Habermas's Contribution to Discourse Ethics and Its Implications for Intercultural Ethics and Organization Theory." In Philosophy and Organization Theory (Research in the Sociology of Organizations vol. 32), edited by Tsoukas, H. and Chia, R., 155-80. New York: Elsevier Press.

Shaw, B. 2000. "Review Essay of Ties That Bind." American Business Law Journal 37: 563-78.

Smith, W. K., and Lewis, M. W. 2011. “Toward a Theory of Paradox: A Dynamic Model of Organizing." Academy of Management Review 36: 381-403. 
Soule, E. 2002. "Managerial Moral Strategies: In Search of a Few Good Principles." Academy of Management Review 27: 114-24.

Soule, E., Hedahl, M., and Dienhart, J. 2009. "Principles of Managerial Moral Responsibility." Business Ethics Quarterly 19: 529-52.

Spicer, A. 2009. "The Normalization of Corrupt Business Practices: Implications for Integrative Social Contracts Theory (ISCT)." Journal of Business Ethics 88: 833-40.

Stansbury, J. 2009. "Reasoned Moral Agreement: Applying Discourse Ethics within Organizations." Business Ethics Quarterly 19: 33-56.

Steinmann, H. 2007. "Corporate Ethics and Globalization: Global Rules and Private Actors." In Business Ethics of Innovation, edited by Hanekamp, G., 7-26. Berlin: Springer. Steinmann, H., and Löhr, A., eds. 1989. Unternehmensethik. Stuttgart: Poeschel.

Steinmann, H., and Löhr, A. 2015. Grundlegung einer Republikanischen Unternehmensethik. Ein Projekt zur theoretischen Stützung der Unternehmenspraxis. In Theorien der Wirtschafts und Unternehmensethik, edited by van Aaken, D. and Schreck, P., 269-309. Berlin: Suhrkamp.

Steinmann, H., and Scherer, A. G. 1997. "Intercultural Management between Universalism and Relativism: Fundamental Problems in International Business Ethics and the Contribution of Recent German Philosophical Approaches." In Europe in the Global Competition, edited by Urban, S., 77-143. Wiesbaden: Gabler. . 1998a. "Corporate Ethics and Global Business: Philosophical Considerations on Intercultural Management." In Ethics in International Business, edited by Kumar, B. N. and Steinmann, H., 13-46. Berlin: DeGruyter.

- 1998b. Interkulturelles Management zwischen Universalismus und Relativismus. Kritische Anfragen der Betriebswirtschaftslehre an die Philosophie. In Zwischen Universalismus und Relativismus: Philosophische Grundlagenprobleme des interkulturellen Managements, edited by Steinmann, H. and Scherer, A. G., 23-87. Frankfurt am Main: Suhrkamp.

Teubner, G., and Korth, O. 2012. Two Kinds of Legal Pluralism: Collision of Transnational Regimes in the Double Fragmentation of World Society. In Regime Interaction in International Law: Facing Fragmentation, edited by Young, M., 23-54. Oxford: Oxford University Press.

Thomas, S. M. 2000. “Taking Religious and Cultural Pluralism Seriously: The Global Resurgence of Religion and the Transformation of International Society." Millennium: Journal of International Studies 29: 815-41.

Walzer, M. 1994. Thick and Thin: Moral Argument at Home and Abroad. Notre Dame, IN: University of Notre Dame Press.

Wempe, B. 2009. Extant Social Contracts and the Question of Business Ethics. Journal of Business Ethics 88: 741-50.

Wittgenstein, L. 2009. Philosophical Investigations, 4th ed. Edited and translated by Hacker, P. M. S. and Schulte, J. Oxford: Wiley-Blackwell.

Wohlrapp, H. 1998. "Constructivist Anthropology and Cultural Pluralism: Methodological Reflections on Cultural Integration." In Ethics in International Management, edited by Kumar, B. N. and Steinmann, H., 47-63. New York: de Gruyter.

. 2014. The Concept of Argument: A Philosophical Foundation. New York: Springer.

Young, M. A., ed. 2012. Regime Interaction in International Law: Facing Fragmentation. Cambridge: Cambridge University Press.

Zuboff, S. 2015. "Big Other: Surveillance Capitalism and the Prospects of an Information Civilization.” Journal of Information Technology 30: 75-89. 